\title{
The Integration of Eastern and Western Culture In Laozi Research
}

\author{
Xi Chen
}

\author{
School of Humanities \& Social Sciences, Xi'an Polytechnic University, Xi'an, Shaanxi 710048, \\ China
}

XIWEST@163.com

Keywords: Laozi research; Chinese and Western culture; Integration

\begin{abstract}
The main purpose of this paper is to promote cross-cultural communication between the Chinese and Western cultures. On the one hand, it helps each other to better understand the collision and integration of the philosophical and cultural of the two sides, and reduces some misunderstandings caused by the cross-cultural exchanges between the Chinese and Western countries. On the other hand, it helps to promote mutual philosophical culture between China and the West. Recognize, understand and absorb, and form a multicultural society to achieve mutual integration. With the rapid development of modern social productivity and technology, globalization has become a major trend in today's world.
\end{abstract}

\section{Introduction}

The word "Dao" first appeared in the golden text, referring to the road people walked, and it was a very specific concept. In the Book of Changes, "Dao" has appeared four times, and its meaning is generated in the specific meaning of the "road"[1]. For example, "Lv Dao Tan Tan" mentioned in "Book of Changes", the "Dao" refers to the road of pedestrians, which means walking on a flat road. Until Laoziproposed the concept of "Dao", "Dao" was sublimated to a philosophical category. And then the meaning of "Dao" was extended from a concrete "road" to many abstract concepts, such as methods, laws, laws of nature, etc[2]. It was generally accepted and recognized by future generations.

"Logos" comes from ancient Greek. Combining many references and research results at home and abroad, the scholars are based on the root of the leg and the core of the meaning to derive the meaning of "Logos"[3]. There are many other meanings, which are summarized as follows: explanation, speaking, telling, language, quotations (the original meaning and central meaning); reason, thought, logic, thinking, spiritual law (derived meaning); calculations, numbers, notes, transcripts, natural laws (derived meaning)[4]. The great Greek philosopher Heraclitus was the first to propose and discuss the concept of "Logos" in the Western world as a philosophical concept.

This paper is a new model represented by two theoretical forms and ideological traits to defend the status and influence of dialectics. Through summarizing the theory and the practical sense, the paper clarifies and correctly interprets the misunderstandings about Laozi and Heraclitus's dialectic thoughts. And it strives to break the gap between people's minds about dialectics, correctly understand dialectics, and promote the development of dialectics. Drawing on the contemporary value of dialectics, the principle of rejuvenating the academic world and contributing to society will restore the vitality of the dialectic.

\section{Laozi's "Dao" and "Name"}

\section{The meaning of Laozi's "Dao"}

The ancient Chinese inhabitants once thought that everything was from a state of chaos. Later, as time went by, the heavens and the earth gradually differentiated and developed from the primitive chaotic state, thus forming a variety of phenomena and things. In the "One Thousand Character Classic" of the Emperor Wu of the Southern Dynasties, the "Cosmic Flood" was expressed in this way. In Tao Te Ching, Lao Tzu regards "Dao" as the root of all things in the world[5]. Through the continuous interpretation of the "Dao", the "Dao" theory was finally put forward and formed a 
systematic theory.

The book of Laozi has always been an important issue for scholars. So far, scholars still have different views on the book of Laozi. At the International Symposium of Guodian Laozi held at Damus University in the United States, Luo Hao of Brown University in the United States tried to use the "Selection" model to summarize the current "Laozi" and the simplified version of Laozi, see in figure 1.

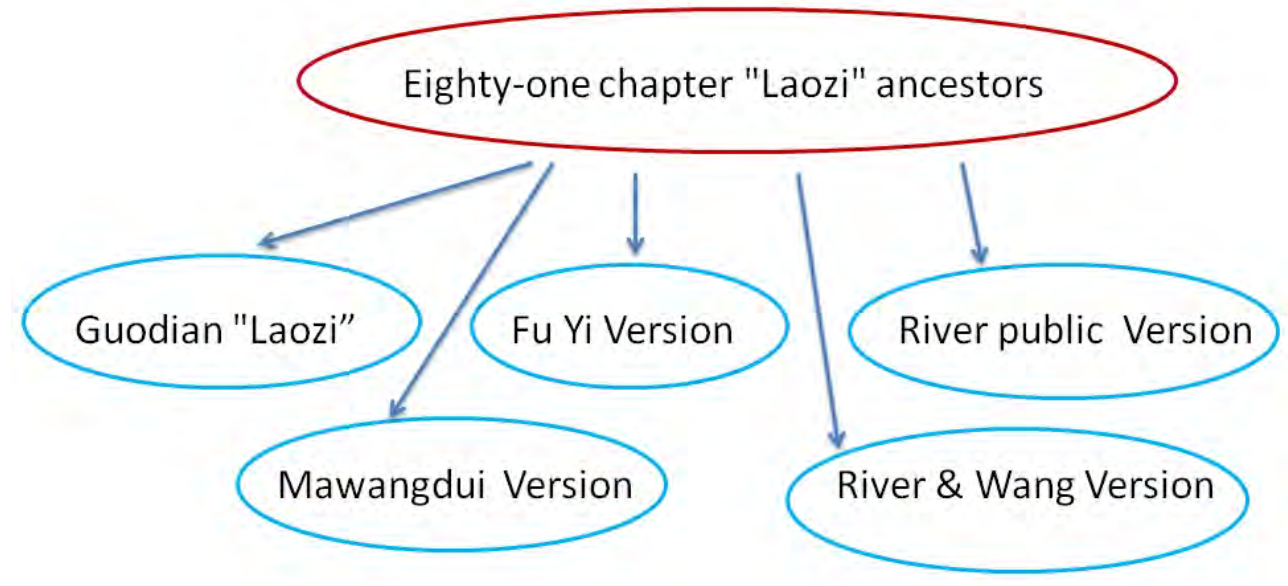

Figure. 1 A possible relationship model between the current Laozi and the simplified Laozi

The ancient sons, because of the facts, are often not made at one time, and there are no times. Most of them are done at any time, that is, by the world. It is not a single article, but there is no certain difference. The compilation of later generations is also influenced by the times, places and subjective factors. The book "Laozi" also experienced a long and unchanging process from appearance to stereotype. Here, we may be able to illustrate the evolution of the book Laozi in figure 2.

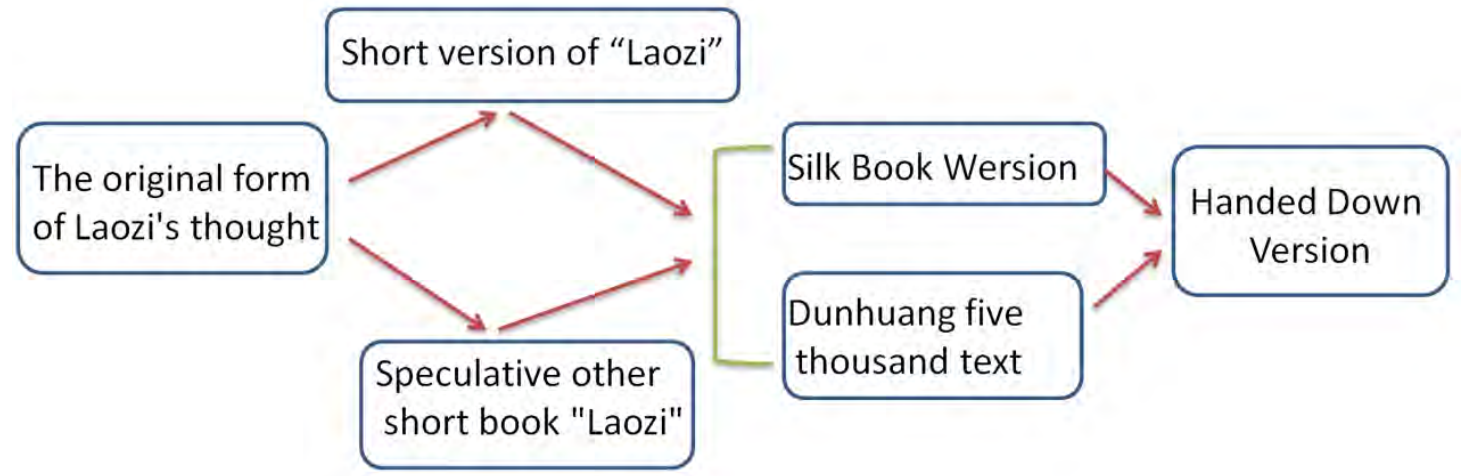

Figure. 2 The Evolution Process Model of Laozi

The Dunhuang Five Thousand Texts are different from the Shadow Song version and the Twenty-two Sons version. However, there are quite a few places in the silk book and the bamboo book. This is probably not accidental. It seems to imply that the Dunhuang five thousand text "Laozi" has an earlier origin. Moreover, the editors of the world's five thousand texts "Laozi" have more than a few words on the "Laozi" sentence, in order to make up the number of words of five thousand. It seems that this view is not very factual. Because many sentences that are not found in Dunhuang's five thousand texts do not exist in the earlier books of the Laozi. This may indicate that the Dunhuang five thousand text "Laozi" did not have these words in the original text, so it is impossible to talk about the deletion of words.

\section{Laozi's "Name"}

The concept of "Name" comes from the first sentence of the opening of the Tao Te Ching. "The road is a way, not a constant road. The name can be named, not a constant name." For this sentence, we can understand that "Dao" is not a universal, eternal "Tao" if it can be expressed in words. If "Name" can be named by language, it is not a universal, eternal "name". 
Therefore, we can understand that Lao Tzu said that the Dao is said to be nothing. In fact, it is based on the idea of naming everything. Therefore, after mentioning that "the Dao can be said, it is very Taoist," he continued to put forward "The name can be named, not a constant name". A name that can be spoken or named is not an eternal name. This name can only be a name that temporarily exists in the world, and will change with time or space. It is a concrete thing that exists objectively. So, what is the eternal "name"? The answer is "nothing." If you don't have something, you can't name it.

\section{The Communication between Laozi and Heraclitus' Dialectics}

\section{The influences of Laozi dialectics on Chinese and western humanities and society}

We can get a consensus from the dialectic comparison between Laozi and Heraclitus. The universal concept contained in the dialectic of them: dialectics is the way in which the world (human and nature) exists. In the world that Laozi understands is which people and nature are united[6]. The fundamental meaning of the universe is consistent with the fundamental meaning of life. Laozi's cognition of the world comes from a perceptual experience. Laozi takes the subjectivity of human beings as the principle, gives meaning to the value of life in all things in the universe. Laozi pays attention to understanding the existence of the world from the perspective of human beings. The law of Laozi's way is "Ran". The Dao is the root of all things. It is the changing body of "have no life".

The "sexuality" of the Tao is to all things, to the life of all things, and to the real thing of the Tao. All things are in accordance with the law of all things, but it is not external, but the internalization of the existence of Ding. "I think it is" is the principle of human existence, the nature of human beings. The way of heaven is white, so it is also inside in existence. In this sense, "the existence of man is the fundamental existence of the world". Therefore, to grasp the fundamental principle of Yu Market, it is necessary for people to reflect inwardly and to understand the true self. The old people think that the nature of human beings is now, people through physical, thus achieving the integration of human beings from the unity of nature and man. Laozi started from the external perceptual experience and rose to the road. People realized the transcendence through the understanding of the inner nature, and realized my transcendence. That is, the human being, the sensible me, rose to the real nature of the nature, and which reached the human existence exists. Through the revelation of the inner transcendence of the Tao, Laozi's dialectics transcends the binary opposition between the subject and the guest, and unites man and nature, revealing the meaning of the existence of the world.

\section{Learning from Laozi and Heraclitus's Dialectical Thoughts}

The world described by Heraclitus is full of poetic and imaginative space. Heraclitus established a general picture of the world with the symbol of dampness, and Logos is the "spoof" that unlocks the world. The true purpose of Heraclitus's dialectics is not to recognize the law, but to look at the "one" behind everything (Logos is here in Heraclitus, but the world is completely separated from people, who is only listen to logic with rationality from the "hidden association", each can grasp the existence of "all things are the same". Heraclitus's understanding of the world stems from the understanding of all things in nature. And he tries to seek everything from the nature of this "uniform unity". The universal law is that Logos creates everything and dominates everything. It is an eternal law. The subjectivity of human beings is embodied in the desire for knowledge of truth and the abandonment, which is from the knowledge and experience of common sense. Sri Lanka, comprehending the truth, reveals my existence in revealing the existence of all things. Logos is the ultimate principle of the existence of all things in the world. People are all grasping logos, which is the external transcendence of all things in the city.

In the process, it transcends the opposition between consciousness and existence, grasps the essence of the world (human and nature) existence, and realizes the realm of the unity of things. The dialectic of Laozi and Heraclitus completes the ontology. The world's concern in the sense of meaning, and beyond the dualistic opposition of the subject and object, reveals the way the world exists. At the same time, we can discover the essential difference between the dialectic thoughts from the consensus, and analyze the differences in the characteristics of the two dialectic thoughts. 
It reveals a different field of application of dialectics, and tries to form a complementary relationship between the two dialectics. This will provide enlightenment for the development of contemporary dialectics.

\section{Conclusion}

The development of humanistic context in contemporary society and the current predicament of dialectics bring about the possibility of understanding between Laozi and Heraclitus's dialectical thinking. Both Laozi and Heraclitus's dialectical thoughts reflect the philosophical essence of the locality and the specific era, which has brought great enlightenment to the development of later dialectics. Under the true form of the two dialectics, carrying forward the Eastern and Western modes of thinking and the spirit of the times will help to achieve the mutual complementarity and integration of the two dialectics, and thus promote the unity of practical rationality, dialectical rationality and theoretical rationality.

\section{References}

[1].Duignan, M., J. Noble, and R. Biddle, Abstraction and Activity in Computer-Mediated Music Production. Computer Music Journal, 2010. 34(4): p. 22 - 33.

[2]. Beltran-Carrillo, V.J., et al., When Physical Activity Participation Promotes Inactivity: Negative Experiences of Spanish Adolescents in Physical Education and Sport. Youth \& Society, 2012. 44(1): p. 3-27.

[3]. Boutard, G. and C. Guastavino, Following Gesture Following: Grounding the Documentation of a Multi-Agent Music Creation Process. Computer Music Journal, 2012. 36(4): p. 59-80.

[4]. Boukouvala, F., et al., Computer-Aided Flowsheet Simulation of a Pharmaceutical Tablet Manufacturing Process Incorporating Wet Granulation. Journal of Pharmaceutical Innovation, 2013. 8(1): p. 11-27.

[5].Xiong, J., An Approach to Evaluating the Physical Education Teaching Quality in Universities and Colleges with Triangular Intuitionistic Fuzzy Information. Journal of Convergence Information Technology, 2013. 8(7): p. 933-940.

[6].Hartzer, C.E., Commentary: Indiana Education Reform and Fiscal Stress: Practitioners' Curiosity. Public Administration Review, 2014. 74(5): p. 614-615. 